\title{
PROTESTA SOCIAL Y PARTICIPACIÓN POLLIIICA DE LOS JÓVENES ESTUDIANTES DE LA UNIVERSIDAD DE CÓRDOBA-COLOMBIA: EL CASO DE UNICOR INFORMAIIVO.
}

SOCIAL PROTEST AND POLIIICAL PARTICIPAIION OF YOUNG STUDENTS FROM THE UNIVERSITY OF CÓRDOBA-COLOMBIA: THE CASE OF UNICOR INFORMAIIVE

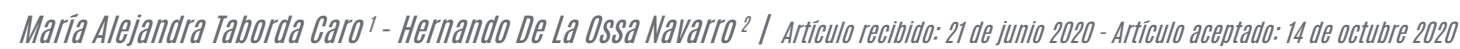

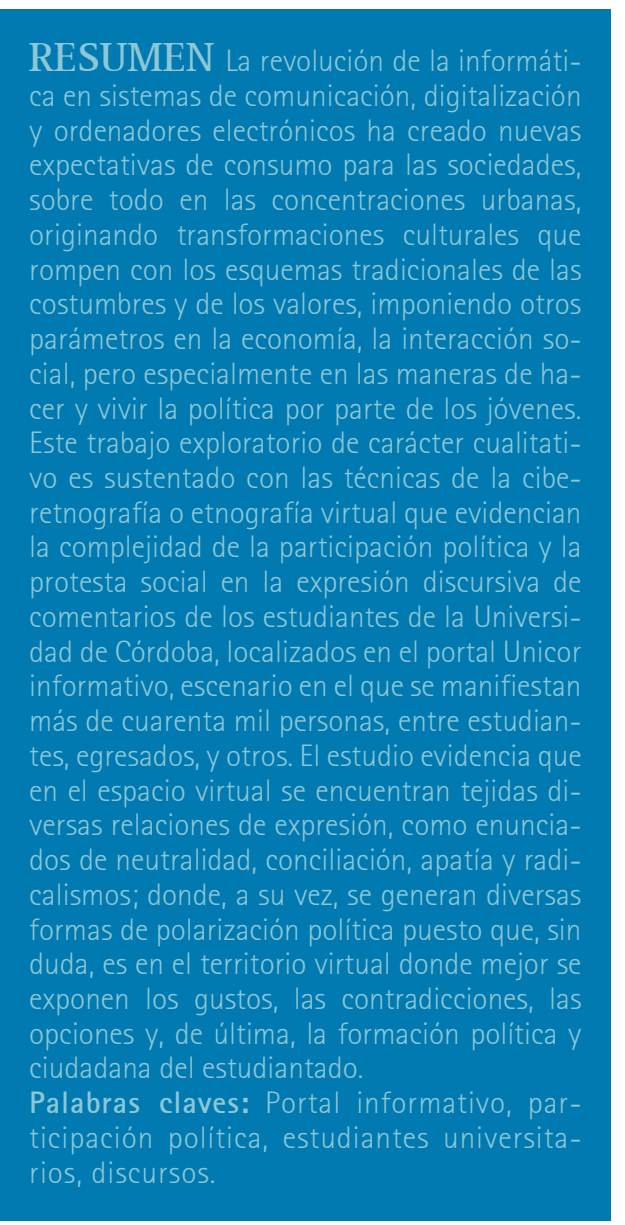

1 Docente Universidad de Córdoba. Coordinadora de la Maestría en Ciencias Sociales. Doctora en Educación. Correo electrónico: Socialescolombia@gmail.com.

\footnotetext{
2 Estudiante de Licenciatura en Ciencias Sociales de la Universidad de Córdoba (IX semestre). Coordinador del semillero Derechos Humanos y Memoria Histórica. Correo electrónico: delaossanando2@gmail.com.
}

"Los jóvenes no abandonaron la política cuando ella los abandonó. Buscaron, animaron y alumbraron otros espacios y modalidades para expresarse y participar ensanchando la esfera de la política" Sarmiento y Chaves

\section{INTRODUCCIÓN}

Los medios de comunicación han sido a lo largo de los años legitimadores de variadas movilizaciones ciudadanas, en ellos se manifiestan diversas formas de enunciación: inconformidades, afinidades, radicalismos e incluso apatía por cualquier temática política. Es así como, a través de Internet, se generan ciberprotestas y debates públicos entre comunidades virtuales e interacciones entre movimientos políticos e internautas que no son mediadas por instituciones informativas formales, puesto que, en algunas plataformas, las redes sociales se constituyen en escenarios de expresión ciudadana (Slimovich, 2012).

Con la irrupción de las TIC, según Montero (2017: 9), "las redes sociales se convirtieron en un elemento importante para mantener y mejorar las democracias actuales"; a la par que modificaron las formas tradicionales de comunicación en las que la segmentación del mensaje cambió en función de los destinatarios. Sin duda, los nuevos medios digitales son ahora más que instrumentos o máquinas, formas de actuar políticamente (Scolari, 2008). Debido a la variedad de textos circulantes, los ciber-grupos en redes sociales como Facebook pueden concebirse como espacios de interacción de géneros multimodales, una vez viralizados estos posts, se introducen y convergen en el flujo de noticias, propiciando diversas reacciones entre sus integrantes (Neira, 2018). Un ejemplo de ello fue el ciclo de movilización estudiantil de las Universidades en Colombia a finales de 2018 y 2019, donde se evidenciaron circulares de apoyo y rechazo en redes sociales que se esparcieron, adaptaron y evolucionaron para cumplir funciones comunicativas relativas a las necesidades de participación 
De Prácticas y discursos

Universidad Nacional del Nordeste

Centro de Estudios Sociales

Año 9, Número 14, 2020, Octubre

ISSN 2250-6942

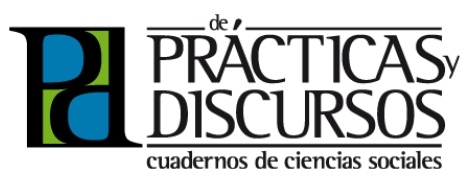

política y protesta social, con el objetivo de tejer el debate por la Educación Superior en mesas asamblearias nacionales y llevar el discurso de la defensa de la educación pública de las paredes, tropeles, comunicados a las redes y las páginas sociales a espacios de concreción política. Con la irrupción de las TIC, la protesta social adopta un nuevo escenario en el que la espacialidad virtual se convierte en la coyuntura clave para la comunicación y la organización más detallada de las movilizaciones llevadas a cabo en el territorio nacional.

En el ámbito de las transformaciones de la mediatización del entorno virtual se dio una introducción de nuevos modos de ejercer mecanismos de participación política y protesta social; sin embargo, Encina (2016), frente a estos eventos, considera que aparecieron dos vertientes de análisis: por un lado, los que piensan que las redes sociales son una nueva dimensión del espacio público que permite que los ciudadanos participen activamente de la vida política; por otro lado, surgen los argumentos que ponen en juicio estos espacios ya que consideran que el discurso político en las redes sociales pierde carácter argumentativo. Es poco profundo, dominado por la velocidad, inmediatez y brevedad, la red no permite el desarrollo de un discurso político genuino en los jóvenes; muy por el contrario, surge lo que Gallardo Paúls y Enguix (2016) Ilaman pseudopolítico, que pierde su posibilidad deliberativa, lejos de un debate serio. No obstante, no se puede desconocer que los nuevos territorios de encuentro socio-político se constituyen en nuevas voces que imprimen autoridad para desarrollar dinámicas argumentativas relevantes en el debate político.

De acuerdo con lo anterior, en este artículo, mediante un proceso de rastreo de los posts subidos al grupo de Facebook llamado Unicor informativo, espacio de expresión más visitado y representativo de la Universidad de Córdoba, en el que interactúan algo más de cuarenta mil cibernautas, se realizará un análisis de las dinámicas de participación política y protesta social de los jóvenes estudiantes de la Universidad de Córdoba-Colombia. Además, se examinarán algunas de las prácticas discursivas presentes en el último gran movimiento estudiantil de finales de 2019, en donde se mostraron nuevas formas de hacer visibles las manifestaciones de inconformismo/apoyo a la estructura político-educativa estatal en medio de las convulsiones socio-políticas que en ese momento definian la vida universitaria a partir del sistema público, particularmente en algunos paises de América Latina. 
De Prácticas y discursos

Universidad Nacional del Nordeste

Centro de Estudios Sociales

Año 9, Número 14, 2020, Octubre

ISSN 2250-6942
PROTESTA SOCIAL Y PARTIICIPACIÓN POLLITICA DE LOS JÓVENES ESTUDIANTES DE LA UNIVERSIDAD DE CÓRDOBA-COLOMBIA: EL CASO DE UNICOR INFORMAIIVO.

SOCIAL PROTEST AND POLIIICAL PARTICIPATION OF YOUNG STUDENTS FROM THE UNIVERSITY OF CÓRDOBA-COLOMBIA: THE CASE OF UNICOR INFORMAIIVE

El documento en su estructura interna, en primer lugar, muestra a través de un grupo de antecedentes recopilados en tres grupos de estudios las principales tendencias para estudiar la participación juvenil hoy en política. En segundo lugar, continúa con una presentación general referida a las nuevas formulaciones desde un campo emergente denominado ciberetnografía, reflexiones teóricas de expresiones metodológicas y sus conexiones con instrumentos y técnicas. En tercer lugar, le sigue una mirada a los movimientos estudiantiles en América Latina, como un contexto que permite comprender los propios en Colombia, para entrar a detallar, en cuarto lugar, la participación de los jóvenes de la Universidad de Córdoba en el movimiento de 2018-2019 en defensa la Universidad Pública desde un portal informativo.

\section{ANTECEDENTES INVESTIGATIVOS}

Con la aparición de nuevas formas para ejercer creativamente la comunicación e informar a las sociedades mediante elementos que facilitan la accesibilidad instantánea a los ciudadanos, Internet y el uso de las redes sociales irrumpen como herramientas que se destacan por su velocidad en el manejo y distribución de la información. Gracias a estos nuevos escenarios que se adaptan eficazmente para el debate político, se rompe con cierto ciclo que censura las formas tradicionales de participación ciudadana, por lo que aflora la libertad de expresión sin temor a la censura, toda una suerte de temáticas políticas del momento. Además, y siguiendo a Gil de Zuñiga, Jung y Valenzuela (2011), como a Salas y Villegas (2015), en la actualidad se considera que los estudios sobre comunicación política deben profundizar la participación política de los ciudadanos jóvenes a través de redes sociales como Facebook, que en cierta medida es la de más fácil acceso por su cobertura en costo.

En las últimas décadas ha surgido una preocupación relacionada con los escasos niveles de participación política de los jóvenes, lo que ha impacto en la calidad y el fortalecimiento democrático de nuestra sociedad. Se requiere propiciar, entonces, nuevos espacios de debate inclusivo e idear acciones concernientes a reenergizar la práctica política de la ciudadanía joven para destacar nuevos roles vitales en la coyuntura democrática.

Algunos estudios sobre la participación de jóvenes en la política están concluyendo que prima el desinterés, la apatía y el 
De Prácticas y discursos

Universidad Nacional del Nordeste

Centro de Estudios Sociales

Año 9, Número 14, 2020, Octubre

ISSN 2250-6942

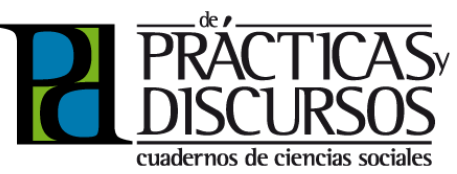

desencanto. Ruiz y Rio (2015) muestran que parecen ser estos los rasgos que con frecuencia se establecen y ejemplifican en las relaciones y acciones en materia de la praxis política de gran parte de los ciudadanos. Aunque estas posiciones se diversifican entre los rangos de edad, son los sujetos más jóvenes quienes se muestran más desnaturalizados de la práctica política, al menos en su dimensión institucional.

Sin embargo, otras posiciones con respecto al debate sobre el nivel de interés de los jóvenes en temas políticos sientan sus argumentos en bases analíticas de desigualdad al considerar que la baja participación política no se debe a que los jóvenes hayan desabrigado su papel dentro de la sociedad civil o que estén distraídos consumiendo productos propios de las TIC (Sánchez, 2016), sino que las élites sociales y políticas ancladas a pedestales clientelares han excluido a los jóvenes de estos escenarios de participación, sin obviar el hecho de que en una sociedad democrática existen múltiples sujetos, versiones y escenarios interesados en develar los sucesos bajo sus premisas discursivas. Por lo cual, Mesa (2007: 358) considera que "el ciudadano recibe distintos mensajes persuasivos con diferente interpretación sobre un mismo hecho".

Otros argumentos acerca del declive en el interés de los jóvenes por la vida pública parecen concentrarse en lo que tradicionalmente se entendía como prácticas cívico-políticas. En este sentido y a modo de ejemplo, algunos autores como García-Galera (2014) y Sánchez (2016) afirman que las redes sociales van más allá de ser solo un medio más de comunicación, para mutar en innovadoras formas de participación política, protesta social y activismo global. En Colombia, un informe de la Defensoría del Pueblo (2020) considera que la participación política en las redes propicia nuevas facultades para la intervención en las decisiones que afectan al plano nacional, que consolidan la intención de la participación ciudadana formalizada en la Constitución política de 1991, concebida dentro de los derechos fundamentales particularmente y con vehemencia llevados al pleno ejercicio por los movimientos estudiantiles y sindicales en su mayoría. Sin embargo, el informe concluiria que hay una inclinación de organizarse políticamente a través de las redes sociales que crece en los jóvenes; gracias al consumo desmedido de productos en los medios digitales, que no impide que se desarrollen ciertas tendencias críticas hacia la realidad.

En este sentido, hay quienes afirman que las redes dinamizaron los discursos de los estudiantes en la misma dirección que 
De Prácticas y discursos

Universidad Nacional del Nordeste

Centro de Estudios Sociales

Año 9, Número 14, 2020, Octubre

ISSN 2250-6942
PROTESTA SOCIAL Y PARTIICIPACIÓN POLLITICA DE LOS JÓVENES ESTUDIANTES DE LA UNIVERSIDAD DE CÓRDOBA-COLOMBIA: EL CASO DE UNICOR INFORMAIIVO.

SOCIAL PROTEST AND POLIIICAL PARTICIPATION OF YOUNG STUDENTS FROM THE UNIVERSITY OF CÓRDOBA-COLOMBIA: THE CASE OF UNICOR INFORMAIIVE

opacaron su presencia argumentativa, en menor medida, fuera de línea. En las investigaciones previas quedó demostrado que los jóvenes en su mayoría presentan un alto grado de activismo en la web, por ser la edad de la experimentación, la facilidad de acceso y por la fácil adaptación al manejo tecnológico; sin duda, las anteriores variables han condicionado la participación política en la web (Montemayor, Peña-Ramos y López, 2019).

Otros trabajos con estudios de casos buscaron comprender cómo se organizan los jóvenes en la acción política para lograr dinámicas y alternativas, y proponerle al país nuevas opciones de participación desde perspectivas socio-históricas y espacios de indagación, análisis y construcción de sentidos; grupos de jóvenes organizados para el trabajo comunitario que los impulsan a configurar propuestas de participación política de acción y compromiso, evidenciando que lo político no es lo electoral, sino la construcción del tejido social, atendiendo a lo anterior Alvarado, Botero y Ospina (2012) evidenciaron los siguientes grupos:

Red Juvenil de Medellín; Red de Comunicación alternativa de Manizales; Movimiento Juvenil Álvaro Ulcué, Norte del Cauca; Colectivo de Pensamiento MINGa de la Universidad del Valle; Ruta Pacífica Jóven, Pereira; Ecoclub Blue Planet, Ciudad Bolivar, Bogotá; Programa Niños, Niñas y Jóvenes Constructores de Paz, Nacional (p. 84).

Por otro lado, Sarmiento (2015) muestra cómo en los medios de comunicación y el debate político se encuentran de manera injustificada miradas estereotipadas sobre la juventud y su participación política. Se declara antagónico este autor a la visión del joven apático y despreocupado por el acontecer político de su sociedad que convive a la par de una imagen totalmente opuesta, a la de un joven filántropo y épico interesado en temas públicos. Se tiene así estas dos representacions del joven político que transita por estas dos narraciones cargadas de prejuicios que invisibilizan, tras una mirada homogeneizadora, las múltiples habilidades y prácticas de las diversas experiencias y subjetivaciones juveniles con relación a su participación política. Pero, sin duda, las nuevas manifestaciones juveniles reflejadas en posturas políticas no se desprenden de los movimientos de la primavera árabe y los indignados, estos últimos surgieron con una especial convocatoria a través de las redes. El 21 de octubre de 2010, cuando dos ciberactivistas españoles generaron en Fa- 
De Prácticas y discursos

Universidad Nacional del Nordeste

Centro de Estudios Sociales

Año 9, Número 14, 2020, Octubre

ISSN 2250-6942

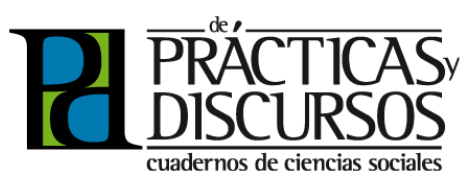

cebook una página con el siguiente eslogan: "Yo soy un joven español que quiere luchar por su Futuro" y un blog en diciembre de 2010 (www.juventudenaccion.info), a través del que se empezaron a citar para la realización de acciones colectivas con una fuerte reflexión de reivindicaciones democráticas. Se dinamizaron a la par otros movimientos como el Ponte en Pie, nacido en enero de 2011, en el foro de Bariloches. Bajo la premisa que la participación de los jóvenes no se desprende de una ciudadanía que es posible de realizar bajo las complejidades y dificultades referidas al género (Machota, Gámez, Fuentes, 2013).

En general, los trabajos se localizan en las variables sociológicas que tienen entre sus objetivos principales el analizar las relaciones y emplazamientos que se marcan en el uso de las redes sociales digitales, además de conocer cómo y en qué medida dichas variables generan desigualdades en la participación politica juvenil. Las metodologias usadas en las investigaciones anteriores varian entre técnicas de investigación cuantitativa y cualitativa, a partir de la realización de diferentes mecanismos para la recolección de los datos.

Finalmente, siguiendo las concepciones online de Van-Dijk (2017) y Hargittai (2002), la red como fuente que permea el acceso al activismo político no es ajena a la brecha digital basada, por una parte, en las desigualdades económicas de acceso y, por otra, en la desigualdad relativa a las habilidades digitales necesarias para participar políticamente de forma online que no es de igual posibilidad y manejo para el conjunto de los jóvenes.

\section{NUEVAS FORMULACIONES METODOLÓGICAS PARA UN CAMPO EMERGENTE: CIBERETNOGRAFÍA}

Las investigaciones referidas a los jóvenes y su presencia en la web han exigido nuevos derroteros no solo teóricos, sino metodológicos. Para este tipo de pesquisas se toma como opción la etnografía virtual, también conocida como ciberetnografía, etnografía digital o etnografía de lo digital, como un método de investigación online más desarrollado dentro de los métodos cualitativos.

A finales de la década de los noventa e inicios del 2000, autores como Escobar (1994) y Miller y Slater (2000), postularon que Internet fuera constituida como un objeto legítimo donde se pudiera aplicar la etnografía. Unos años después, investigaciones realizadas por Ardébol, Estalella y Domínguez (2003) y 
De Prácticas y discursos

Universidad Nacional del Nordeste

Centro de Estudios Sociales

Año 9, Número 14, 2020, 0ctubre

ISSN 2250-6942
PROTESTA SOCIAL Y PARIICIPACIÓN POLLITICA DE LOS JÓVENES ESTUDIANTES DE LA UNIVERSIDAD DE CÓRDOBA-COLOMBIA: EL CASO DE UNICOR INFORMAIIVO.

SOCIAL PROTEST AND POLIIICAL PARTICIPATION OF YOUNG STUDENTS FROM THE UNIVERSITY OF CÓRDOBA-COLOMBIA: THE CASE OF UNICOR INFORMATIVE

Hine (2004) aplicaron estas metodologías a sus campos de acción académica, concluyendo que la etnografía virtual está sujeta a cambios básicos en los procedimientos de análisis de la etnografía clásica, que observa con detalle las formas en que se experimenta el modelado en los usos de una tecnología digital. En las etapas en que comenzó la eclosión social de las redes sociales, se dio la introducción de la etnografía al medio virtual, detallando un nuevo desplazamiento hacia un campo emergente de investigación en el que se podían desarrollar exitosamente trabajos que midieran el impacto social de Internet en los diversos espacios sociales como el de la participación política. Sin embargo, se requirió renovar la manera como se trabajaba en la obtención de datos mediante el uso de los métodos etnográficos tradicionales aplicados al ciberespacio. En este sentido, la aplicación de este método a nuestra investigación busca comprender cómo se vinculaban los jóvenes a experiencias de acción política participativa en el mundo virtual como dinámica alternativa de construcción de Nación frente a acontecimientos sociohistóricos y políticos significativos de la última década en Colombia.

Las formas en que la discursividad política se desarrolla en la web nos ofrece un campo abierto para la aplicación de las nuevas formas metodológicas y conceptuales emergentes, para abordar el análisis de las dinámicas y las formas de emplazamiento del ciberespacio aplicando técnicas para la adquisición de datos, análisis e interpretaciones hechas por autores y participantes en diversos roles dentro del conjunto multimodal de los espacios virtuales. Así, el ciberespacio puede hacer posible una nueva etnografía multisemiótica gracias a que se condesan nuevas técnicas de acceso a la información, puesto que se consolida la validación de los datos al crear nuevos enlaces para contrastar las fuentes, algo que la etnografía clásica denomina "triangulación", para evitar confiar en una sola fuente de información, lo que permite analizar la información y abre nuevas maneras de organizar la interpretación y la argumentación; y permite que las referencias cruzadas y el desarrollo de vínculos (links) hacia diversos escenarios de la web en los distintos momentos de la investigación permeen con mayor facilidad y amplien su margen de difusión para conocer otros puntos de convergencia (Torres, 2008).

En este sentido, se consolida a la ciberetnografía o etnografía virtual con la traspolación de los métodos tradicionales de obtención de datos que se mudan de una comunidad física a una 
De Prácticas y discursos

Universidad Nacional del Nordeste

Centro de Estudios Sociales

Año 9, Número 14, 2020, Octubre

ISSN 2250-6942

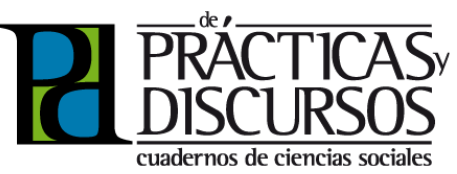

virtual, y que han requerido de una importante innovación tanto en las técnicas de recolección de datos como de su interpretación, considerando que los tiempos y espacios tienen otras manifestaciones. Por lo cual, en la emergencia de comunidades virtuales, de redes y grupos de interés que se aglomeran bajo intereses comunes, ha permitido y requerido renovar las técnicas de obtención de información, como también la compresión que tenemos sobre los nuevos modos comunicativos y cómo se presentan hoy (Aguilar y Méndez, 2015).

\section{LOS MOVIMIENTOS ESTUDIANTILES EN AMÉRICA LATINA: LA PRESENCIA DE LOS JÓVENES EN LA DISCUSIÓN POLITICA.}

Las protestas sociales con la participación de gremios estudiantiles en América Latina, desde las últimas décadas del siglo pasado hasta las recientes protestas estudiantiles en Colombia, han sido demarcadas con ciertos rumbos teóricos que intentan explicar el nudo gordiano que ata esta coyuntura definida por el neoliberalismo que, para autores como Núñez (2019: 40), se da como "un discurso cultural eficiente en producir procesos de subjetivación orientados a la acumulación y la privatización permanente de lo público, lo que David Harvey, por ejemplo, ha llamado acumulación por desposesión".

Un ejemplo de ello son las llamadas manifestaciones "los pingüinos siguen marchando", ocurridas entre 2006 y 2012 en Chile, donde las principales motivaciones de las movilizaciones estudiantiles, secundarias y universitarias, se vincularon con el lucro en la educación y la obtención de ganancia. No obstante, el hecho más importante de estas movilizaciones se concentró en la búsqueda de espacios democráticos que aún no se han restaurado desde la dictadura de Augusto Pinochet. Adicionalmente y de la misma manera que en los demás paises, una demanda muy seria por el aumento del presupuesto educativo, especialmente para las universidades, a la democratización del gobierno universitario, permitiéndole a la representación estudiantil voz y voto (Vommaro, 2016).

Brasil también fue epicentro de monumentales movilizaciones en 2013, cuando miles de jóvenes se movilizaron expresando las limitaciones y los retrocesos en materia social y educativa, además de un anacronismo en los avances políticos-sociales y en las políticas de inclusión social que vivió ese país en los últi- 
De Prácticas y discursos

Universidad Nacional del Nordeste

Centro de Estudios Sociales

Año 9, Número 14, 2020, Octubre

ISSN 2250-6942
PROTESTA SOCIAL Y PARTIICIPACIÓN POLLITICA DE LOS JÓVENES ESTUDIANTES DE LA UNIVERSIDAD DE CÓRDOBA-COLOMBIA: EL CASO DE UNICOR INFORMAIIVO.

SOCIAL PROTEST AND POLITICAL PARTICIPATION OF YOUNG STUDENTS FROM THE UNIVERSITY OF CÓRDOBA-COLOMBIA: THE CASE OF UNICOR INFORMATIVE

mos años. Y el caso mexicano con el movimiento estudiantil de nombre \#YoSoy132, que surgió a partir de la declaración de 131 estudiantes de la Universidad Iberoamericana donde, de forma general, expresan que su accionar no solo abarca el tema educativo, sino que busca cambios más profundos en los medios de comunicación y en el sistema político nacional (Vommaro, 2015). La recepción que han tenido los jóvenes en cuanto a participación política y movilización estudiantil puede leerse de acuerdo con elementos característicos como: las formas performativas que usan, es decir, los lugares y eventos en donde se emplazan las acciones de movilización; las formas de visibilidad que emplean, ya sean en escenarios públicos o en los atractivos digitales; el compromiso público que colectivos juveniles adquieren en sus prácticas cotidianas y, por último, el shock mediático, político y académico que genera el agrupamiento de los caracteres anteriores, y que contribuye a posicionar el discurso juvenil de acción política en los planos centrales y en las agendas de gobierno. Lo particular del Brasil es la posibilidad de recrear movilizaciones estudiantiles de variadas reivindicaciones en las que se articulan reclamos relacionados con la estratificación urbana, especialmente los impactos del mercado inmobiliario, la vivienda y el derecho al tránsito libre y sin restricciones, para desestabilizar la segregación espacial que no permite la apropiación de la ciudad por parte de amplios sectores de la población, en especial de jóvenes de las periferias que se vienen manifestando por el derecho al ocio y a la posibilidad de manifestarse con formas estéticas y artísticas para intervenir y apropiarse de la ciudad con murales, grafitis o pixaçãos (Vommaro, 2016).

\section{NOCIONES Y CONTEXTO: PARO NACIONAL DE LAS UNIVERSIDADES PÚBLICAS DE COLOMBIA 2018-2019}

En Colombia, los historiadores del movimiento estudiantil reconocen que 1971 representa la mayor movilización en la historia de Colombia de estudiantes de variados niveles e intereses. A diferencia de movimientos anteriores, involucró a casi todas las universidades públicas y privadas, adicionalmente fue la primera vez que una protesta de estudiantes logró congregar a otros sindicatos y gremios bajo una misma consigna: "Por una educación nacional, científica y de masas" (Acevedo y Crucelly, 2011).

En los años noventa se activa este movimiento de estudiantes 
De Prácticas y discursos

Universidad Nacional del Nordeste

Centro de Estudios Sociales

Año 9, Número 14, 2020, Octubre

ISSN 2250-6942

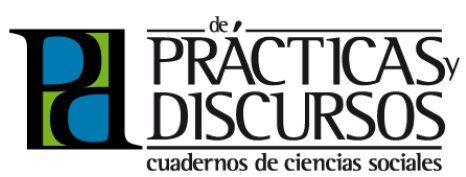

en el contexto del asesinato del aspirante a la presidencia Luis Carlos Galán. El 11 de marzo de 1990, los colombianos estaban convocados a votar para elegir sus representantes en el Senado, Cámara, Asamblea Departamental, Concejo, Alcaldias y juntas administradoras locales. Y, por otro lado, se consolidó el movimiento que impulsó la Constitución del 91 en Colombia por un grupo de jóvenes universitarios que se manifestaron en la calle organizadamente y de forma contundente contra una clase política anacrónica y una constitución precaria en espacios de participación, por lo que exigieron la modernización y ampliación de la democracia y cambios importantes en el Estado social de derecho.

Una propuesta que surgió a partir de un movimiento social arrojó cerca de 2 millones de votos en la consulta con el Senado, Cámara de Representantes, Asamblea Departamental, Juntas Administradoras Locales (JAL), Concejo Municipal y alcaldes. La pregunta que quedó para la historia: ¿Qué le quedó a futuro a un movimiento estudiantil que logró trasformar a través de un cambio constitucional la manera de participar en los destinos del país? Según Arteaga, Bautisma y Cabrales (2019), se puso en acción para el país una democracia participativa de la que aún hoy, y a pesar de las diversas reformas en materia de participación política ciudadana suscitadas posteriormente, estos mismos movimientos de jóvenes no logran disfrutar.

En este escenario, en 2011, la Mesa Amplia Nacional Estudiantil (Mane) se comprometió con la reorganización nuevamente del movimiento estudiantil, que se encontraba subyugado debido a fuerzas de poder generadas con el conflicto armado y los caciques políticos que se distribuian, y aún lo hacen, las instituciones del Estado para mantener su hegemonía política. Se logró de manera exitosa y creativa activar los movimientos de buena parte de las universidades del territorio nacional, públicas y no púbicas, contra el proyecto de Reforma a la Educación Superior diseñado por el gobierno de Juan Manuel Santos al Congreso Nacional, llegando a un conceso y "normalizando" las actividades nacionales.

Nuevamente, las protestas sociales-estudiantiles se reactivan en 2019, impulsadas desde un movimiento más amplio de América Latina, donde se expresa un desasosiego frente a la creciente desfinanciación de la educación pública, por un lado, y un replanteamiento de soluciones a problemáticas internas de amplia envergadura de las universidades, por el otro, como lo plantea una columna del periódico El Espectador (2018: 2): 
De Prácticas y discursos

Universidad Nacional del Nordeste

Centro de Estudios Sociales

Año 9, Número 14, 2020, 0ctubre

ISSN 2250-6942
PROTESTA SOCIAL Y PARTIICIPACIÓN POLLITICA DE LOS JÓVENES ESTUDIANTES DE LA UNIVERSIDAD DE CÓRDOBA-COLOMBIA: EL CASO DE UNICOR INFORMAIIVO.

SOCIAL PROTEST AND POLIIICAL PARTICIPATION OF YOUNG STUDENTS FROM THE UNIVERSITY OF CÓRDOBA-COLOMBIA: THE CASE OF UNICOR INFORMAIIVE

El problema de fondo: en Colombia, para tener una buena educación debes tener la plata para pagar un colegio y una universidad privada a precios exorbitantes que siguen aumentando o ser un genio excepcional que se gane todas las becas posibles. Pero la educación no es un lucro ni un logro, es un derecho fundamental que debería estar garantizado para todas las personas, incluso las que viven en los territorios más apartados de la Colombia profunda.

En esta emergencia educativa se reactivaron nuevamente mesas concertadas de diálogo con el gobierno nacional. Sin embargo, las dificultades en la negociación prolongaron la protesta, y al paro se unieron otros sectores sociales, lo que agudizó la problemática nacional, paralizando amplios sectores y agremiaciones de la industria. Gracias a las crecientes movilizaciones y manifestaciones públicas de descontento que adelantaron los estudiantes se decretaron el 11 de octubre 2019 por las 32 universidades públicas, a voz unísona, unas medidas de restructuración político-educativas al gobierno para que se atiendan las problemáticas referentes al déficit histórico en infraestructura y funcionamiento económico de las Universidades públicas, y para revisar las pautas con las que se ofrece el crédito educativo del Instituto Colombiano de Crédito Educativo y Estudios Técnicos en el Exterior (Icetex) a los estudiantes.

En general, las peticiones de este movimiento estudiantil se pueden resumir así: garantizar los recursos para el funcionamiento de las universidades públicas; reformas sustantivas de la Ley 30 de 1992; cambios en la designación de presupuesto ya que, durante los últimos 25 años, en los ingresos para las universidades públicas se ha mantenido con el mismo rubro. Se requería entonces un nuevo régimen de transferencias para las universidades oficiales. No obstante, el liderazgo estudiantil, en ese momento, se ve representado por la naciente Unión Nacional de Estudiantes de la Educación Superior (Unees) que fue producto de los Encuentros Nacionales de Estudiantes de Educación Superior (Enees) realizados en marzo y septiembre de 2018, cuando se discutió la manera de colocar a la Educación Superior en el contexto de servicio social con amplias posibilidades de acceso. La amplitud de este movimiento llevó a conformarse nuevos grupos de estudiantes de universidades públicas al lado de universidades privadas, como centros técnicos y tecnológicos públicos, reafirmando y consolidando una nueva generación de estudiantes y sectores 
De Prácticas y discursos

Universidad Nacional del Nordeste

Centro de Estudios Sociales

Año 9, Número 14, 2020, Octubre

ISSN 2250-6942

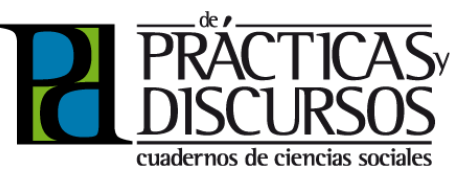

industriales comprometidos con la organización política nacional (Desde abajo: la otra posición para leer, 2018).

Las nuevas reacciones del movimiento estudiantil y los diferentes sectores económicos y sociales que se unieron a la protesta frente a las deficientes políticas nacionales para el desarrollo del territorio demuestran, una vez más a la sociedad colombiana, que se ha comprendido la realidad de la educación nacional y las políticas de desarrollo como un desbalance inclinado hacia sectores que siempre han sido favorecidos. El movimiento estudiantil pone en el lente crítico el modelo mercantil impuesto al sistema educativo, puesto que la educación se debe prestar en las mejores condiciones para que se permita al estudiante educarse para construir una nación incluyente. En este sentido, Sánchez, Martínez y Ramírez (2012: 302) consideran que:

El joven estudiante es una densidad subjetiva, una multiplicidad subjetiva, recargada como función social a la institución educativa, en este caso, la universidad. Puesto que, de un lado, ha de formarse como ciudadano en los marcos también de esta institución, pero, además, como sujeto académico y moral, y como sujeto productivo. Actúa y se mueve en el escenario curricular desde el punto de vista de su ser sujeto, y también en el escenario político reconocido a la universidad como institución, en su sistema de representación.

El panorama, por lo tanto, se desdibuja, por un lado, en la inexistencia de una posición abierta del gobierno para entablar un diálogo mancomunado, la represión constante por parte de agentes del Estado y el ataque por parte de medios de comunicación nacionales y locales a la legítima protesta; y, por el otro, en una creciente polarización interna en el movimiento estudiantil respecto a las formas de llevar a cabo la práctica de la protesta como manifiesto descontento contra las posiciones del gobierno nacional y las administraciones locales.

Finalmente, las problemáticas y situaciones de contexto nacional y local donde se desarrollan temáticas de intenso debate con una multiplicidad de participantes, roles y propósitos, asociados a formaciones discursivas, nos encaminan a estudiar esos nuevos espacios donde también convergen nuevas narrativas para comprender y analizar las relaciones con respecto a los nuevos lugares, virtuales, por ejemplo, donde se traslada el contexto mismo. Ya es común encontrar esta expresión en diversos medios e in- 
De Prácticas y discursos

Universidad Nacional del Nordeste

Centro de Estudios Sociales

Año 9, Número 14, 2020, Octubre

ISSN 2250-6942
PROTESTA SOCIAL Y PARTIICIPACIÓN POLLITICA DE LOS JÓVENES ESTUDIANTES DE LA UNIVERSIDAD DE CÓRDOBA-COLOMBIA: EL CASO DE UNICOR INFORMAIIVO.

SOCIAL PROTEST AND POLIIICAL PARTICIPATION OF YOUNG STUDENTS FROM THE UNIVERSITY OF CÓRDOBA-COLOMBIA: THE CASE OF UNICOR INFORMAIIVE

vestigaciones: "La salud de la democracia depende, en gran parte, de los jóvenes". En este hilar discursivo se señala también que la ciudadanía activa, como la participación de los individuos en la vida y los asuntos públicos, se consolida en la formación profesional y en las vivencias de la vida universitaria de manera importante. Las vivencias políticas de los jóvenes se convierten en una de las actividades más importantes para lograr una transición positiva hacia la edad adulta, aunque la participación y el compromiso de los estudiantes puede considerarse un fin en sí mismo; las instituciones universitarias educan de esta manera con planes de estudio, asignaturas o currículos cargados o no de intencionalidad para la formación ciudadanía.

Sin duda alguna, en la vida universitaria, la socialización y la participación o no en los espacios democráticos, la presencia en la consolidación de las agendas de normativas con estudiantes, las maneras como se desarrollan los canales electorales y los medios para su expresión, lo que se denomina el currículo oculto, están determinadas como ningún otro hecho en la manera de ser ciudadanos y en la manera de entender lo público y sus compromisos; un arraigo o no del individualismo frente a los sentimientos de compromisos colectivos. De este modo, Vommaro (2015: 76) sugiere que:

Estos movimientos se enmarcan en el proceso de paulatina ampliación de derechos y de creciente consideración de las diversidades sociales que se produjo en América Latina en los últimos años y que involucró especialmente a los jóvenes, que muchas veces fueron los principales beneficiarios de estos nuevos derechos y también los principales luchadores para lograrlos.

Lo anterior es lo que se denomina también como la política de la presencia, y quienes mejor están evidenciando los resultados de estas intencionalidades son las redes de sociabilidad en los espacios virtuales, es decir que, "para la comprensión de la experiencia universitaria desde una perspectiva más amplia se necesita, no sólo una etapa dedicada a la adquisición de conocimientos para la formación profesional, sino la experiencia universitaria como espacio efectivo y privilegiado para la construcción de experiencia vital y condición sociopolítica de los jóvenes" (Sánchez, Martínez y Ramírez, 2012: 287).

Es aqui donde se crean nuevos "ambientes", en los que se puede interactuar y aportar libremente a una conversación o un debate 
De Prácticas y discursos

Universidad Nacional del Nordeste

Centro de Estudios Sociales

Año 9, Número 14, 2020, Octubre

ISSN 2250-6942

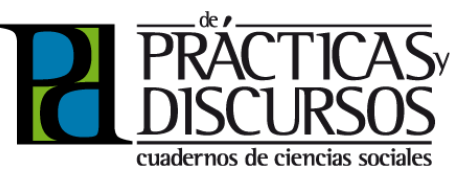

sin las lógicas normativas de una clase. La construcción de conceptos o de tareas se realiza al instante, pudiendo ser cristalizada en segundos una idea de convocatoria, de reunión o de acción de rechazo. A favor de ese inmediatismo se tiene que los "límites" o barreras geográficas no existen.

Se requiere con urgencia una mayor formación universitaria que le dé elementos a los estudiantes para la observación y la comprensión crítica de su realidad y de su entorno, un cúmulo de habilidades para la expresión pertinente y adecuada de sus opiniones y propuestas a través de la palabra, la escucha y el respeto hacia las ideas de los demás, la empatía a través del diálogo. Por otro lado, se requiere de la presencia de cierta autonomía estudiantil como uno de los elementos existentes en la academia, como es el del llamado debate académico. Sin embargo, las universidades han logrado que un fuerte grupo de la población joven estudiantil mundial se sienta desilusionada con la politica general y en clara desventaja frente a los adultos en las leyes y medidas parlamentarias, y es que la gobernanza de la sociedad y de los centros educativos se hace sin ellos.

\section{LA UNIVERSIDAD DE CÓRDOBA Y SU PORTAL INFORMATIVO: EXPRESIÓN JOVEN DE LA POLITICA}

La Universidad de Córdoba (Unicor) es una de las instituciones de Educación Superior de carácter estatal más importantes de la región. Desde sus inicios, en la década de los 60, se ha visto envuelta cada vez más en afinadas redes clientelares y de corrupción, convirtiéndose en un fortín de la élite política local. También ha sido cooptada por grupos armados ilegales como guerrillas y paramilitares. Durante los noventa e inicios del 2000 fue el escenario de disputas de fuerzas políticas e intereses de actores paramilitares, ejerciéndose prácticas de terror hacia el movimiento estudiantil y el movimiento sindical. Entre asesinatos selectivos, secuestros, amenazas y exilios, fueron las prácticas más recurrentes durante aquella época que algunos la consideran como la toma a sangre y fuego de la Unicor (Taborda, 2019). En la actualidad cuenta con 17.123 estudiantes distribuidos en 6 sedes, incluida la central ubicada en la ciudad de Montería. Esta responde dentro de su misión a las demandas sociales de la región mediante la formación de recursos humanos que se ajustan a las dinámicas y potencialidades locales distribuidas en torno 
De Prácticas y discursos

Universidad Nacional del Nordeste

Centro de Estudios Sociales

Año 9, Número 14, 2020, 0ctubre

ISSN 2250-6942
PROTESTA SOCIAL Y PARTIICIPACIÓN POLLITICA DE LOS JÓVENES ESTUDIANTES DE LA UNIVERSIDAD DE CÓRDOBA-COLOMBIA: EL CASO DE UNICOR INFORMAIIVO.

SOCIAL PROTEST AND POLIIICAL PARTICIPATION OF YOUNG STUDENTS FROM THE UNIVERSITY OF CÓRDOBA-COLOMBIA: THE CASE OF UNICOR INFORMAIIVE

a las demandas de técnicos, tecnológicos, pregrados y postgrados, lo cual ha llevado a posicionarla como pilar de la Educación Superior a nivel regional por los estándares e indicadores que contempla su estructura académica.

Sin embargo, la panorámica actual de la Universidad de Córdoba demanda la construcción de nuevos espacios de participación en donde no solo se atiendan las voces de aquellos que ocupan algún puesto de poder -o que pueden acceder a espacios de diálogos fuera de la web-, sino que también permita según Ventura, (2016), "evaluar el grado de legitimidad de prácticas discursivas en el desarrollo argumentativo del discurso" (p, 2), específicamente alrededor de los sitios virtuales es donde se manifiestan aquellas "voces", jóvenes en su mayoria, tipificando y estructurando el acceso a las redes virtuales informativas con temas de debate multiestamentario dentro del claustro universitario, posibilitando tomar parte a la Universidad en unas nuevas formas de territorialidad en las comunidades virtuales (Torres, 2008).

Lo mismo, a lo largo de la historia de las universidades públicas han existido múltiples formas de pronunciamientos personificados en su mayoria por movimientos estudiantiles y sindicales-, apoyados desde los exteriores e interiores de los claustros universitarios; son llevados a la práctica mediante actos constitucionales de protesta social. Sin duda, la protesta social a lo largo de la historia de la Universidad de Córdoba ha estado influida por múltiples actores que buscan promover ciertas políticas, obtener ciertos intereses 0 mejorar las condiciones de la educación dentro del claustro, etc. En esta medida se han incorporado diversos rituales estéticos que han diversificado formas de hacer visibles manifestaciones de inconformismo/apoyo a la estructura político-educativa estatal, como se visibiliza y se pone en evidencia en el uso de las redes sociales como Facebook. En estas redes sociales aparecen grupos de información y debate que viralizan acciones de protesta social transformando un nuevo escenario donde la espacialidad virtual se convierte en la coyuntura clave para la organización y una comprensión más detallada de las movilizaciones en el territorio nacional. Por ejemplo, en marzo de 2012 nace el grupo Unicor informativo, apostado en la red social Facebook. Según las políticas expuestas por el admistrador, tiene por función general servir como enlace de comunicación entre las directivas de la Universidad y los estudiantes, intencionalidad que resultó muy fructífera en cuanto al uso de los espacios cibernéticos. 
De Prácticas y discursos

Universidad Nacional del Nordeste

Centro de Estudios Sociales

Año 9, Número 14, 2020, Octubre

ISSN 2250-6942

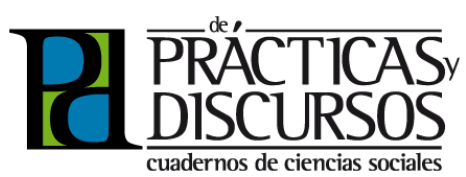

Sin embargo, este espacio evolucionó por sí mismo para sobredimensionar dicho fin, ya que aproximadamente la gran mayoría de los casi 50 mil participantes adscritos al grupo -entre estudiantes, egresados, directivos institucionales de la Universidad y terceros- lo usa para fines políticos y comerciales, y de desahogos personales, además de exteriorizar sus desahogos académicos. No obstante, otras personas vieron en la página un lugar perfecto para la exposición de temas clave a debatir entorno a las problemáticas internas de la Universidad, algo similar a un conclave estudiantil, de aqui que se partiera por denunciar cosas significativas como el malestar generado por los almuerzos estudiantiles ofrecidos por bienestar universitario y las manifestaciones discursivas salidas de tono por parte de la administración. Cabe resaltar que en este grupo virtual se han pasado por alto algunos de los pliegos de exigencias estudiantiles expuestos a la administración de la Universidad, las censuras y hasta agresiones por parte de agentes del Estado contra la infraestructura y los estudiantes.

De este modo, se fue orquestando una forma innovadora de ejercer el mecanismo constitucional de la protesta social donde según Neira, (2018): "Las redes sociales son algo más que un fenómeno de su época: pone al alcance de los actores movilizados determinados recursos materiales y simbólicos, cuyo aprovechamiento se considera valioso o necesario en sus respectivas culturas y coyunturas políticas" (p. 56). Así, se puede encontrar en este grupo un cúmulo de discursos políticos que vieron su ápice en las pasadas manifestaciones estudiantiles de finales de 2018 y 2019, estructurados en un álgido debate que se trasladó también a escenarios virtuales. Durante esta coyuntura asimismo se fraguaron y polemizaron temas de indole interna, como los concernientes a la continuación de las clases o la persistencia en términos de temporalidad del paro nacional, que era a su vez una forma de protesta para mostrar el inconformismo en materia de política educativa nacional.

Nos encontramos, entonces, con características específicas de estas comunidades virtuales imbuidas en los espacios de debates políticos tales como, según Brunner, (1994): "los términos dramáticos que la alimenta cada día con pequeños conflictos, batallas de palabras y un flujo constante de trascendidos y rumores" (p. 6), donde el mensaje político contiene en su sentido amplio: datos, opiniones, argumentos, sentimientos, valoraciones, llamamientos críticos, etc. (Montes, Parrales, Gómez y Manzanares, 2011). 
De Prácticas y discursos

Universidad Nacional del Nordeste

Centro de Estudios Sociales

Año 9, Número 14, 2020, 0ctubre

ISSN 2250-6942
PROTESTA SOCIAL Y PARIICIPACIÓN POLLITICA DE LOS JÓVENES ESTUDIANTES DE LA UNIVERSIDAD DE CÓRDOBA-COLOMBIA: EL CASO DE UNICOR INFORMAIIVO.

SOCIAL PROTEST AND POLIIICAL PARTICIPATION OF YOUNG STUDENTS FROM THE UNIVERSITY OF CÓRDOBA-COLOMBIA: THE CASE OF UNICOR INFORMATIVE

En este sentido, el tipo de actividad comunicativa que se genera entre las personas tiene consecuencias para la toma de decisiones y es por ello que son vitales para los jóvenes no organizados en movimientos o colectivos, los chicos anónimos, la existencia de estos espacios de plataformas por cuanto permiten la expresión y la construcción de lenguajes frente a las realidades del conjunto de la vida universitaria, que poco a poco va trasladando el muro como viejo depositador de la inconformidad a la red. Sin duda, la política se organiza hoy en torno a las comunicaciones, a tal punto esto es cierto que Bruner (1994: 45): considera que, "en las sociedades democráticas contemporáneas, ambas la política y la comunicación son la fuente principal de relación entre gobernantes y gobernados".

El objeto de estudio de esta investigación está en describir cómo se manifiesta la protesta social y la participación política de los jóvenes estudiantes de la Universidad de Córdoba, desde este espacio denominado Unicor informativo, tomando como punto de reflexión los movimientos que acompañaron el paro de 2019. A nivel procedimental, para el análisis de presente artículo, fue fundamental el uso y configuración de un archivo, puesto que se usaron alrededor de 44 documentos distribuidos en noticias de portales virtuales oficiales de los diarios nacionales y locales de la siguiente manera: noticias distribuidas de la revista Semana y el diario El Tiempo. También se contemplaron los diarios locales como La Flecha, El Meridiano de Córdoba y la cadena radial Olimpica Stereo, en estos últimos su rastreo se hizo mediante lo que se conoce por "compartir", opción que da Facebook cuando se hace uso de esta red social, y se ubicaron sus titulares en el portal web de La Flecha.

Por otro lado, se esbozaron 8 comentarios ubicados en el grupo de Facebook de Unicor informativo, después de una revisión general, de acuerdo con la periodización usada para la investigación; representan una totalidad semejante a las expresiones que se usaron en el grupo virtual. Estas valoraciones se hicieron después de una lectura cuidadosa de los cometarios y teniendo en cuenta que eran los que más tenían trascendencia en el grupo debido a factores virtuales como "comentarios" dentro de los mismos y lo que se conoce como "reacciones", opciones que en cierto punto del debate virtual demandaban afinidades y discernimientos.

Finalmente, la documentación guía que propició la parte teórica para el anclaje discursivo se distribuyó en 33 documentos 
De Prácticas y discursos

Universidad Nacional del Nordeste

Centro de Estudios Sociales

Año 9, Número 14, 2020, Octubre

ISSN 2250-6942

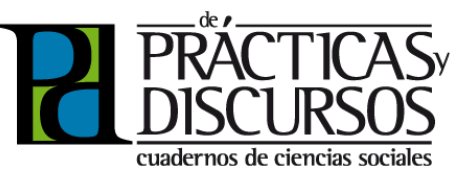

expresados en artículos científicos, informes y libros de autores que abordaban temas relacionados con la presente investigación, y que su adecuado uso y sus aportes permitían fortalecer nuestra investigación. Toda esta documentación fue depositada en una rejilla que daba cuenta de un orden temporal que, a su vez, determina modalidades enunciativas, prácticas y conceptos, los cuales se encuentran aquí descritos. En este sentido, se identificaron enunciados que hacian referencia y, por lo tanto, le otorgaban sentido a nuestro objeto de estudio. La recolección de la información secundaria se realizó desde una perspectiva de rastreo teórico que permitió dar cuenta del estado del arte sobre los discursos y prácticas de participación política, y en la cual se evidenciara la vinculación de los jóvenes.

Bajo el paradigma cualitativo de la ciberetnografía, autores como Alvarado, Borelli y Vommaro (2012: 67) consideran que, "en este sentido, estamos hablando de un proceso que permite construir datos que, al ser procesados, habrán de articularse en nuevas narrativas, discursos y textos sobre el objeto-sujeto de estudio", explicitadas nuestras intenciones y definidos correctamente los datos recogidos. En un segundo momento de la investigación se procede a analizar, desde las distintas posturas teórico-metodológicas planteadas anteriormente, lo que es la participación política y protesta social en las redes sociales, donde se llevaron a cabo dos tipos de estrategias: (i) revisión documental, incluida la de documentos de política educativa institucional, y (ii) seguimiento a casos particulares de expresión política en el portal Unicor informativo, así como las implicaciones que han tenido en las políticas nacionales y locales. Por último, se pone especial énfasis en el análisis de cómo la participación política de los jóvenes, desde la esfera virtual, ha transformado el ejercicio formal de los derechos constitucionales de la protesta social y cómo son legitimados por los diversos actores inmersos en la acción social del activismo en la red.

En este orden de ideas, los sujetos que consignan estas prácticas discursivas, adscritos a este grupo virtual, se pueden clasificar de la siguiente manera: los apáticos, quienes se abstienen de intervenir, es decir, aquellos que renuncian de manera tajante a ejercer plenamente sus derechos de expresión. Los neutros, que actúan como espectadores pasivos y quienes solo se limitan a mirar para estar de acuerdo y/o desacuerdo, pero no intervienen activamente. Los conciliadores, pueden participar activamente, en tanto que su voz es mediadora. Participantes activos y los 
De Prácticas y discursos

Universidad Nacional del Nordeste

Centro de Estudios Sociales

Año 9, Número 14, 2020, Octubre

ISSN 2250-6942
PROTESTA SOCIAL Y PARTIICIPACIÓN POLLITICA DE LOS JÓVENES ESTUDIANTES DE LA UNIVERSIDAD DE CÓRDOBA-COLOMBIA: EL CASO DE UNICOR INFORMAIIVO.

SOCIAL PROTEST AND POLIIICAL PARTICIPATION OF YOUNG STUDENTS FROM THE UNIVERSITY OF CÓRDOBA-COLOMBIA: THE CASE OF UNICOR INFORMAIIVE

radicales, los cuales presentan sentadas enunciaciones de oposición y en cierta forma de violencia física o simbólica frente posturas no afines (Serrano y Serrano, 2009). Además, en varias de sus formas de enunciación usan cierto argot humoristico y palabrería para poner al discurso frente a la discusión sobre posibles resultados en la acción política.

En esta medida citaremos variados comentarios de jóvenes estudiantes pertenecientes al grupo virtual para evidenciar algunos de los caracteres ya mencionados frente a la coyuntura del paro a nivel nacional/local. De este modo, al localizar y tomar las manifestaciones discursivas, se encontraron varios comentarios antagónicos de inconformismo; por ejemplo, el de un estudiante cuya identidad no pudo se constatada, ya que ocultó todos los caracteres que ofrece Facebook para identificar a una persona, en otras palabras, usó lo que comúnmente se denomina como perfil "fake", en donde expresó de manera apática lo siguiente:

Buenas tardes. Queridos representantes de la UNEES, compañeros que no quieren dar clase a toda costa y borregos; debido a sus protestas, disturbios y mala gestión al momento de hacer valer los derechos de nosotros los universitarios (...) le están quitando la oportunidad de que gran parte de la comunidad estudiantil que sí quiere dar clases y posteriormente terminar este semestre no lo haga. (Unicor informativo, 2018).

Cabe resaltar que se omiten algunos términos del vocabulario popular por ser considerados como soeces. No obstante, aqui, dentro de la red, se reflejan posiciones antagónicas a favor o en contra, un hecho vital ya que los estudiantes del movimiento estudiantil generalmente se reúnen para estudiar posiciones que no son la mayoría de veces antagónicas. Bajo esta modalidad se encuentra todo tipo de posturas con una enorme gama de criterios, desde los que contestan de manera razonada bajo la ley de los argumentos y las evidencias, los que participan con sus sentires y presunciones, los que abiertamente exponen sus nombres y procedencias hasta los que se esconden en identidades falsas; unos y otros se enfrentan, de manera discursiva, donde la competencia por la retórica no es más importante que la posibilidad de la expresión franca y libre.

Para el caso que nos ocupa, nos encontramos con estudiantes que exponen su inconformidad en la gestión política que se le 
De Prácticas y discursos

Universidad Nacional del Nordeste

Centro de Estudios Sociales

Año 9, Número 14, 2020, Octubre

ISSN 2250-6942

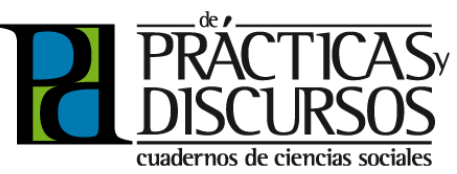

ha dado al paro, a tal punto de desistir del pliego de exigencias postulado al gobierno nacional. Sin embargo, otros estudiantes expresan cierto discurso conciliador. En otras de las publicaciones, un estudiante manifiesta lo siguiente:

A pesar de todas las inconsistencias que ha llevado el paro en la Universidad de Córdoba, debido a que en verdad no hay una verdadera democracia (...) pero seamos críticos, seamos capaces de ver la problemática, no se trata de estar en paro o en vacaciones como muchos lo están, se trata de ejercer nuestro papel como ciudadanos, exigir nuestros derechos (...) háganse escuchar, todas las otras Universidades siguen en paro, infelizmente no somos capaces de ver una problemática social grave por preocuparnos por nuestro bien común, son actitudes como esas las que tienen al país así (Unicor informativo, 2018).

La esencia de este enunciado, que en su naturaleza se parece a otros muchos que buscan llamar a la cordura, al análisis y a la preocupación del colectivo, en términos de armonizar las polémicas suscitadas a partir de la adopción del paro como mecanismo de protesta, en últimas es la reacción de un estudiante a una asamblea que buscaba evaluar la problemática y ejercer juicios críticos con respecto a lo que se había logrado con el ejercicio de la protesta y la participación política. La falta de un interlocutor inmediato que responda en forma de rechazo o de aprobación le da vía libre a un sinnúmero de pareceres que se sienten más seguros publicando en las redes, en las que tradicionalmente no se contesta con amplios argumentos, sino con emoticones o frases cortas, por lo que se está creando un lenguaje de lo político y la participación diferente, con códigos e intereses nuevos.

De esta manera, emergió una nueva forma de poner en juicio público, a través de redes sociales, cierto inconformismo, a veces radical, por parte de un considerable grupo de estudiantes. Nos encontramos con un joven que se expresó de la siguiente manera:

Compañeros, cuando comenzó todo esto nos pareció muy chévere que nos sacaran de clase y nos "salvarán" de un parcial con un saloneo, pero vean las consecuencias de esto. Le hemos dado el poder a un grupo de 10 o 20 estudiantes. Amigo estudiante y compañero usted no le ha firmado nada a ellos. ¿Estamos en paro porque lo dice quién? (...) El paro no sirve de nada. El gobierno feliz con 
De Prácticas y discursos

Universidad Nacional del Nordeste

Centro de Estudios Sociales

Año 9, Número 14, 2020, Octubre

ISSN 2250-6942
PROTESTA SOCIAL Y PARTIICIPACIÓN POLLITICA DE LOS JÓVENES ESTUDIANTES DE LA UNIVERSIDAD DE CÓRDOBA-COLOMBIA: EL CASO DE UNICOR INFORMAIIVO.

SOCIAL PROTEST AND POLIIICAL PARTICIPATION OF YOUNG STUDENTS FROM THE UNIVERSITY OF CÓRDOBA-COLOMBIA: THE CASE OF UNICOR INFORMAIIVE

que cancelen el semestre (...) Sea autónomo de sus decisiones muchos estamos obligados a estar en paro, apoye ideas que de verdad sirvan para el bien de todos (para los que estamos y los que vienen) (Unicor informativo, 2018).

Las expresiones aquí reflejadas exponen un desagrado respecto al manejo que se le dio al paro interno en conexión con el paro nacional. Aunque refleja cierta emotividad, pocas veces admisible en un debate político, esboza algunas de las consecuencias comprobables que han acarreado las medidas del paro como forma de protesta. También están otros sujetos que emiten enunciados que reflejan cierta neutralidad por la problemática nacional entorno al debate por las políticas de educación nacional. Uno de ellos esboza lo siguiente:

Mi posición frente al Paro. Es que el Paro iba bien, cuando era de los Estudiantes, del clamor, ya cuando la UNEES y ASPU se adueñaron de todo, cambiaron las cosas. Petro no tenía que subirse tampoco a la tarima en Bogotá, eso restó credibilidad ante los sectores politicos que estaban apoyando $y$ de una tuvieron que retirarse y abstenerse, ${ }^{\star} E S T O$ LO SABE TODO EL MUNDO*; No estoy defendiendo al gobierno, tampoco diciendo que Petro sea mal Senador, bla bla bla... estoy tratando de ser neutro (no tibio) ante una problemática en específico. Entonces es cuando las personas que creemos tener formación crítica, debemos detenernos y reconocer que este no será el gobierno que cure lo que ningún otro ha logrado en materia de Educación, mucho menos cuando (...) Dejen al gobierno quieto que nosotros ya con eso nos encargamos de garantizar su educación con calidad (...) Les dejo esa inquietud, esperando que se razone un poco en la materia. Un Estudiante queriendo ser Neutro (Unicor informativo, 2018).

Es de resaltar esta última posición, ya que en nuestro rastreo mayoritariamente se evidenció escepticismo y falta de propuestas frente a un número menor, pero existente, que intenta dar luces, educar criterios para actuar de manera razonada, libre, actuando en derecho. No se resalta la existencia de líderes, grupos en este espacio, todos actúan bajo el mismo nivel de importancia y someten sus ideas al escarnio público.

También algunos medios de comunicación locales, tales como El Meridiano, La Flecha y Olímpica Montería (cadena radial), juga- 
De Prácticas y discursos

Universidad Nacional del Nordeste

Centro de Estudios Sociales

Año 9, Número 14, 2020, Octubre

ISSN 2250-6942

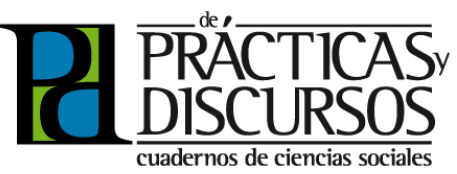

ron un papel crucial en este escenario a partir de titulares que deslegitimaban el accionar estudiantil. Por ejemplo: "¿Defienden la educación superior o a los capuchos?", titular de El Meridiano de Córdoba en su portal de Facebook y posteriormente eliminado. Por su parte, el portal web La Flecha enuncia lo siguiente: "Vandalismo en Unicórdoba: no son estudiantes, son delincuentes: Jairo Torres, rector" (La Flecha, 2017).

A raíz de estos pronunciamientos, se vio en redes sociales una masiva movilización de jóvenes universitarios exigiendo, entre otras cosas, que se dejara de promover la estigmatización y la discriminación social del movimiento estudiantil de la Universidad de Córdoba. Otro enunciado rastreado en la revista Semana (2019: 20) plantea que:

En el debate hay acusaciones y recriminaciones de parte y parte. Los alumnos acusan al Gobierno de reprimir y estigmatizar la movilización social. Por su lado, agentes del Estado señalan que ellos no coartan el derecho a protestar (...) En medio del cruce de palabras vuelve a tomar fuerza la posibilidad de expedir una ley que reglamente la protesta social.

Posiblemente el estudio de estos nuevos lenguajes y formas de participación nos estén explicando que el alejamiento en la participación política de los jóvenes se refleja en la desconfianza hacia las instituciones y actividades en la esfera pública. En el mismo sentido se visibilizan los modos y las prácticas en los que la politización desencadenó toda una serie de producciones simbólicas a través de diversos tipos de prácticas por medio de canales, medios y tecnologías que se alejaron relativamente de las vias institucionales conocidas, donde formaron y reafirmaron la importancia de las expresiones que adquiere la participación política entre los jóvenes.

La participación en el espacio virtual fue fundamental para los precedentes que se presentaron ante las directivas de la Universidad de Córdoba, los cuales tributaron, a su vez, en lo expuesto ante el gobierno nacional en materia de mejoramiento de la calidad educativa nacional. Así mismo, Vommaro (2015: 20-21) sustenta estas nociones aludiando que:

Las nociones de apatía, desinterés o desencanto aludían a la falta de legitimidad y de compromiso entre los jóvenes hacia determinadas formas de la política; es decir, no significó el rechazo a la política como tal, entendida como discurso y como práctica relacionados con la construcción social de 
De Prácticas y discursos

Universidad Nacional del Nordeste

Centro de Estudios Sociales

Año 9, Número 14, 2020, Octubre

ISSN 2250-6942
PROTESTA SOCIAL Y PARTIICIPACIÓN POLLITICA DE LOS JÓVENES ESTUDIANTES DE LA UNIVERSIDAD DE CÓRDOBA-COLOMBIA: EL CASO DE UNICOR INFORMAIIVO.

SOCIAL PROTEST AND POLIIICAL PARTICIPATION OF YOUNG STUDENTS FROM THE UNIVERSITY OF CÓRDOBA-COLOMBIA: THE CASE OF UNICOR INFORMAIIVE

lo común. Entonces, el desinterés, la apatía o desencanto no tienen por qué traducirse en la idea de que las nuevas generaciones no valoraban las cuestiones públicas o, en otras palabras, que se trataba de generaciones despolitizadas. Por el contrario, los diagnósticos sobre el alejamiento y el descompromiso podrían permitirnos dar cuenta del modo en que se produjo un distanciamiento de los jóvenes de la política entendida en términos representativos e institucionales.

Finalmente, el análisis de este portal apostado en Facebook nos deja ver cómo las múltiples miradas y las formas de ejercer protesta y participación política ya no se dan solo desde las prácticas tradicionales, sino que hay una transgresión y un desplazamiento, forzado algunas veces, que tienen fuerte acogida en la población joven. Así mismo, la nitidez, la brevedad y la vivacidad de los enunciados no ponen en riesgo, en cierta medida, a los calificativos expresados para generar posiciones de debate a través de los discursos expresados en donde usar perfiles "fake", por ejemplo, constituiría lo que se llamaría una "capucha virtual" para evitar la censura y los ataques de aislamiento a los individuos que lleguen a expresar posiciones diferentes a las asumidas por las mayorías.

\section{CONCLUSIÓN}

El uso de las redes sociales se puede tomar como complemento para la participación política de los jóvenes universitarios. Sobre la importancia de la mediación en la educación ciudadana y política, los autores no tienen miradas unánimes, algunos creen que se ha perdido profundidad argumentativa $y$, por el contrario, los jóvenes buscan seducción o manipulación, dependiendo el interés. Para otros, la gran mayoría de los actores y enlaces participantes en el discurso político en las redes sociales provoca escenarios de debate más igualitarios, en los que los usuarios demuestran sus puntos críticos y conjeturas con absoluta tranquilidad. Terceros autores afirman que estamos frente a meros sujetos consumidores de contenido imparcial que no generan gran impacto en el ejercicio político de un Estado debido a factores como la desigualdad en el acceso a redes de navegación web y la falta de políticas de inclusión en las TIC.

Los nuevos dispositivos de comunicación e información, en donde se agencian las redes sociales, no solo se caracterizan por ser canales fundamentales de expresión y visibilidad de los colecti- 
De Prácticas y discursos

Universidad Nacional del Nordeste

Centro de Estudios Sociales

Año 9, Número 14, 2020, Octubre

ISSN 2250-6942

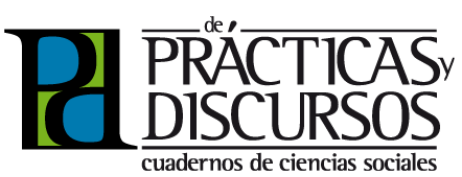

vos sociales, sino que conciernen como componentes o pilares de referencia donde se constituyen y consolidan estas organizaciones. De este modo, la web se convierte, por un lado, en un territorio de participación política en donde se produce una disputa por su control; $y$, por otro, se agenda de forma regulada una pluralidad de mediaciones internas para nuevos miembros que se adhieren, por lo que se constituyen, de forma itinerante, en frentes alternativos para la difusión de realidades sociales frente a los grandes medios masivos y corporativos.

En este sentido, dentro de la manifestación de los jóvenes estudiantes participantes del portal web Unicor informativo hemos encontrado una diversidad de trazos enunciativos que expresa múltiples subjetividades. Por ejemplo: la tan anhelada paz se ha mantenido marginal en las discusiones de los participantes del portal en cuestión; los temas son coyunturales en la medida en que se toman del momento o del instante histórico $y$, de ellos, las posiciones son tomadas por el sentir inmediato, sin mucha reflexión y análisis de coyuntura, desde una descripción histórico-política.

Por tanto, el uso de los entornos virtuales como medios para llegar a un público definido propicia una visión estratégica, un enfoque de ciberdemocracia, inhabilitando esa imagen peyorativa respecto al uso de las redes virtuales en materia de participación política. De esta manera, surge un nuevo posicionamiento en el marco de los discursos de político-educativos de los jóvenes de la Universidad de Córdoba, proliferando, con ciertas medidas y restricciones, formas convexas de comunicación en la producción e intercambio o flujo de la información. Finalmente, esta investigación se articula a un cúmulo de posiciones teóricas que tributan en la conducción de un nuevo formato en el tablero de los espacios de expresión ciudadana, colocándola en la esfera de activos de opinión pública.

Para concluir, en el plano político nacional se perciben recesiones, rezagos y limitaciones que se enlazan con redes que tensionan y fortalecen actitudes y patologías de desconfianza, sospecha, escepticismo, apatía y radicalismos con relación a las instituciones encargadas de velar por los aportes en materia de participación política de los colectivos juveniles. Sin embargo, se ha visto un despliegue en el reconocimiento de prácticas de resistencia, a veces performativas, que les permiten cuestionar y sensibilizarse en torno a su participación, en donde se ponen de manifiesto espacios de sociabilidad e interacción que fluctúan en ámbitos de disputas, confluencias e 
De Prácticas y discursos

Universidad Nacional del Nordeste

Centro de Estudios Sociales

Año 9, Número 14, 2020, Octubre

ISSN 2250-6942
PROTESTA SOCIAL Y PARTICIPACIÓN POLLIIICA DE LOS JŌVENES ESTUDIANTES DE LA UNIVERSIDAD DE CÓRDOBA-COLOMBIA: EL CASO DE UNICOR INFORMAIIVO.

SOCIAL PROTEST AND POLITICAL PARTICIPATION OF YOUNG STUDENTS FROM THE UNIVERSITY OF CÓRDOBA-COLOMBIA: THE CASE OF UNICOR INFORMATIVE

intereses políticos mediados por relaciones de poder que transversalizan las dimensiones generacionales para mostrar el fondo sobre el cual se soportan las problemáticas societales.

\section{BIBLIOGRAFIA}

ACEVEDO, Á Y CRUCELLY, D. (2011). Movilización y protesta estudiantil en Colombia (1971). Una lectura desde la organización gremial por el cogobierno universitario y la memoria de protagonistas y testigos. Anuario de Historia Regional y de las Fronteras, (16)221.

AGUILAR Y MÉNDEZ, M.D.G. (2015). Etnografía Virtual, un acercamiento al método y a sus aplicaciones. Estudios Sobre Las Culturas Contemporáneas. Época lii, (XXI)41, 67-96.

ALVARADO, S.V.; BORELLI, S. Y VOMMARO, P.A. (2012). Juventud y prácticas políticas en América Latina: comprensiones y aprendizajes de la relación juventud-política-cultura en américa latina desde una perspectiva investigativa plural. En Alvarado, S.V. Borelli, S. y Vommaro, P.A. (eds.) Jóvenes, políticas y culturas: experiencias, acercamientos y diversidades (p. 352). Buenos Aires: Clacso: Homo Sapiens. Disponible en Http://Bibliotecavirtual. Clacso.Org.Ar/Clacso/Gt/20121207040846/Jovenes_Politica_ Cultu"Anatomía de la protesta social" (2019). En Semana, 1-2.

ARDÉBOL, E.; ESTALELLA, A. Y DOMINGUEZ, D. (2003). Introducción: La mediación tecnológico en la práctica etnográfica. Catalunya: Universita Oberta de Catalunya.

ARTEAGA, J.; BAUTISTA, L.; CABRALES, J. Y GARCÍA HERREROS, M. (S.F). Las Protagonistas De La Séptima Papeleta. Revista Nova Et Vetera. Disponible en Https://Www.Urosario.Edu. Co/Revista-Nova-Et-Vetera/Cultura/Las-Protagonistas-De-LaSeptima-Papeleta/.

BRAN, A. (2018, 28 DE OCTUBRE). Unicor Informativo. Obtenido de Unicor Informativo: Https://Web.Facebook.Com/ Groups/293908944014689/Search?Q=Andres\%20bran

BRUNNER, J.J. (1994). Comunicacion y politica en la sociedad democratica. Seminario "Políticos y Comunicadores: Interacción 
Y Compromisos. Disponible en Http://Www.Geocities.Com/Brunner_Cl/Konrad.Html?200512, 1-8.

CAÑAS, J.S. (2013). Comunicación política en redes sociales: caso: páginas en Facebook y Twitter de Norman Quijano, Óscar Ortiz y Will Salgado como candidatos a alcaldes durante la campaña electoral 2012 en El Salvador. Antiguo Cuscatlán: Tesis. Universidad Centroamericana.

CASTELLANOS, R.M.; MARÍN, M.O. Y MONTIEL, LE. (2011). Tecnologías de la comunicación y política 2.0. Espacios Públicos, 72-84.

COIUTTI, N. (2015). Discurso político y redes sociales: los tweets De CFK en la campaña electoral 2011. Letra. Imagen. Sonido LI.S., 93-115.

CORONADO, A. (2018, 26 DE OCTUBRE). Unicor Informativo. Obtenido De Unicor Informativo: Https://Web.Facebook.Com/ Groups/293908944014689/?Post_Id=2222520641153500

CHAVES, M. Y SARMIENTO J. (2015). Jóvenes y participación política. Vaivenes de una relación compleja. Voces En El Fénix, Año 6, 51, 96-103. Disponible en Http://Www.Vocesenelfenix.Com/

DEFENSORÍA DEL PUEBLO (2020, 15 DE JUNIO). Centro Nacional De Memoria. Disponible en Https://Www.Google.Com/Searc $\mathrm{h} ? \mathrm{Q}=$ Participaci\%C3\%B3n+Pol\%C3\%Adtica+En+Colombia\&tRlz=1 c1chbd_Esco839co839\&0q=Participaci\%C3\%B3n+Pol\%C3\%Adtic attAqs=Chrome.1.69i57j0l7.2041j0j8\&tSourceid $=$ Chromectle=Utf-8

ESPECTADOR, E. (2018, 15 DE NOVIEMBRE). Si No Incomoda No Es Protesta (pp.1-2).

ENCINAS, L.G. (2016). Argumentación y discurso político en Twitter. Análisis de la campaña presidencial argentina 2011. Aposta, 39-66.

ESCOBAR, A. (1994). Welcome To Cyberia. Notes On The Anthropology Of Cybeculture. Current Anthropology, 211-223.

GARCÍA-GALERA, M.C. (2014). Jóvenes comprometidos en la red: el papel de las redes sociales en la participación social activa. Revista Científica De Educomunicación, 35-43. 
De Prácticas y discursos

Universidad Nacional del Nordeste

Centro de Estudios Sociales

Año 9, Número 14, 2020, Octubre

ISSN 2250-6942
PROTESTA SOCIAL Y PARTICIPACIÓN POLITIICA DE LOS JÓVENES ESTUDIANTES DE LA UNIVERSIDAD DE CÓRDOBA-COLOMBIA: EL CASO DE UNICOR INFORMATIVO.

SOCIAL PROTEST AND POLITICAL PARTICIPATION OF YOUNG STUDENTS FROM THE UNIVERSITY OF CÓRDOBA-COLOMBIA: THE CASE OF UNICOR INFORMATIVE

GALLARDO, B. PAÚLS, S. Y ENGUIX, O. (2016). Pseudopolítica: el discurso político de las redes sociales. Valencia: Universitat de València.

GIL DE ZUÑIGA, H.J. (2011). Social Media, Use For News And Individuals Social Capital, Civic Engagement And Political Participation. Journal Of Computer En Mediated Communication.

HARGITTAI, E. (2002). Second-Level Digital Divide: Differences In People's Online Skills. First Monday, 1-19.

HERRERA, J.A. (2018, 30 DE OCTUBRE). Unicor Informativo. Obtenido De Unicor Informativo: Https://Web.Facebook.Com/ Groups/293908944014689/?Post_ld=2285249798213917

HINE, C. (2004). Etnografía Virtual. Disponible en Http://Www. Antropologiavisual.Com.Ar/Archivos/Hine0604.Pdf: Colección Nuevas Tecnologías Y Sociedad. Editorial Uoc.

JAN A.G.M VAN-DIJK. (2017). Digital Divide: Impact Of Access. The International Encyclopedia Of Media Effects. Https:// Doi.Org/10.1002/9781118783764.Wbieme0043.

LEER, D.A. (2018, 11 DE NOVIEMBRE). Estudiantes. A parar para Avanzar. jViva el paro nacional! (pp. 1-6).

MACHOTA, M.; GÁMEZ, J. Y FUENTES (2013). Feminismos 2.0 y 15-M: cuestionando los cambios en la esfera pública. Disponible en https://dialnet.unirioja.es/servlet/ articulo?codigo $=7494441$

MAZZUCHINO, M.G. (2018). Entre la agresión y la reivindicación: ironia, parodia y sátira en comentarios al Facebook del presidente mexicano. Infoling, 191-216.

MESA, R.Y. (2007). La comunicación política y los nuevos medios de comunicación personalizada. Ámbitos, 16, 355-366. ISSN: 1139-1979.

MILLER, D.Y. (2000). The Internet. An Ethnographic Approach. Berg, Oxford. Berg: Oxford.

MONTERO, A.C. ET AL. (2017). Comunicación política y redes sociales. Sevilla: Egregius. 
MONTES, M.C.; PARRALES, J.A.; GÓMEZ, J.M. Y MANZANARES, E.R. (2011). Reflexiones sobre la comunicación política. Espacios Públicos, (14)30, 85-101.

MONTEMAYOR, D.D.; PEÑA-RAMOS, J.A. Y LÓPEZ, F.R. (2019). La participación política online de los jóvenes en México, España Y Chile. Revista Científica De Educomunicación. Comunicar, (Xxvii)61, 83-92.

NEIRA, C.C. (2018). Análisis de las prácticas discursivas activistas producidas en la comunidad de Facebook Universitario Informado durante las movilizaciones estudiantiles en Chile (2011-2013). Barcelona: Universidad Pompeu Fabra.

NÚÑEZ, S.V. (2019). Neoliberalismo: medios, política y revueltas. Conexión,12, 137-149. ISSN: 2305-7467.

PAÚLS, B.G. Y OLIVER, S.E. (2016). Pseudopolítica: El discurso político en las redes sociales. Valencia: Departamento De Teoria De Los Lenguajes Y Ciencias De La Comunicación, Universitat De València.

RICAURTE, A. (2018, 9 DE NOVIEMBRE). Unicor Informativo. Obtenido De Unicor Informativo: Https://Web.Facebook.Com/ Groups/293908944014689/Search?Q=Buenas\%20tardes.\%20 queridos\%20representantes\%20de\%20la\%20unees

SALAS, A.R. Y VILLEGAS, J.S. (2015). La participación de los medios de comunicación en La arena política: aproximación desde la ciencia política. En Ciencia Politica: Perspectiva Multidisciplinaria (pp. 200-221). Tirant Lo Blanch.

SÁNCHEZ, F.A.; MARTíNEZ, J.C. Y RAMÍREZ, L.G. (2012). Condición política juvenil en la universidad: resultados de investigación en la Universidad Nacional de Colombia, Sede Bogotá. En Alvarado, S.A.; Borelli, S. y Vommaro P. A. (eds.) Jóvenes, políticas y culturas: experiencias, acercamientos y diversidades (pp. 352). Buenos Aires: Clacso: Homosapiens. Disponible en Http://Bibliotecavirtual.Clacso. Org.Ar/Clacso/Gt/20121207040846/Jovenes_Politica_Cultu

SÁNCHEZ, M.Á. (2016). Jóvenes, Internet y participación politica. Un análisis de desigualdades. Universitat Oberta De Catalunya. Internet Interdisciplinary Institute (In3), 1-18. 
De Prácticas y discursos

Universidad Nacional del Nordeste

Centro de Estudios Sociales

Año 9, Número 14, 2020, octubre

ISSN 2250-6942
PROTESTA SOCIAL Y PARTICIPACIÓN POLITIICA DE LOS JÓVENES ESTUDIANTES DE LA UNIVERSIDAD DE CÓRDOBA-COLOMBIA: EL CASO DE UNICOR INFORMATIVO.

SOCIAL PROTEST AND POLITICAL PARTICIPATION OF YOUNG STUDENTS FROM THE UNIVERSITY OF CÓRDOBA-COLOMBIA: THE CASE OF UNICOR INFORMATIVE

SARMIENTO, J. Y CHAVES, M. (2015). Jóvenes y participación politica: vaivenes de una relación compleja. Voces en el Fénix, 51, 97-103.

SERRANO, J.L. Y SERRANO, J.L. (2009). La participación política ciudadana. Sus límites y controles institucionales en el caso mexicano. Estudios Políticos, (9)16, 9-45.

SCOLARI, C. (2008). Hipermediaciones: elementos para una teoria de la comunicecion digital interactiva. Barcelona: Gedisa.

SLIMOVICH, A. (2012). Apuntes sobre las discursividades políticas en el Facebook de Mauricio Macri. Revista Tram[P]As de la comunicación y la cultura. Issn 1668-5547. № 72, 71-78.

TORRES, S. M. (2013). Memecracia en Lima: plebiscito de revocatoria a Susana Villarán. Fes Comunicación, 1-16.

TORRES, M.À. (2008). Ciberetnografía: comunidad y territorio en el entorno virtual. En Ardèvol, Eisenda (ed.) La Mediación Tecnológica En La Práctica Etnográfica (pp. 1-195). Valencia: Ankulegi Antropologia Elkartea.

"VANDALISMO EN UNICÓRDOBA: NO SON ESTUDIANTES, SON DELINCUENTES: JAIRO TORRES, RECTOR" (2017, 20 DE OCTUBRE). En La Flecha, p. 1.

VENTURA, A.S. (2016). Argumentación y discurso político en Twitter. Análisis De La Campaña Presidencial Argentina 2011. Aposta. Revista De Ciencias Sociales, 69. Disponible en Http:// Apostadigital.Com/Revistav3/Hemeroteca/Asuray1.Pdf, 39-66.

VOMMARO, P. (2015). Juventudes y políticas en la Argentina y en América Latina. Tendencias, conflictos y desafíos. Buenos Aires: Grupo Editor Universitario. 